Blet, Boticario de Su Magestad y maior de los $\mathrm{R}^{\mathrm{s}}$. Exercitos; y con la aprobacion del $\mathrm{S}^{\mathrm{r}}$. Intendente de los $\mathrm{R}^{\mathrm{s}}$. Ex ${ }^{\text {tos }} \cdot \mathrm{D}^{\mathrm{n}}$. Fran ${ }^{\mathrm{co}}$. Antonio Domezain. Junio tes de 1781"7.

No debió ser éste de 1780 el único envío remitido al Jardín de Algeciras desde el Monasterio de la Santa Espina; en el catálogo preparado por Luis Neé se hace mención expresa a la procedencia de estas plantas, señalando con una B. las crecidas sobre semillas remitidas desde el Monasterio vallisoletano; hasta un total de 16 hemos contado en el catálogo de 1781 con la indicación "B. La Espina, el R. D. Villares"; de ellas ninguna se encuentra presente en el catálogo remitido en 1780 y hoy conservado entre los fondos del Archivo del Palacio Real.

En cualquier caso, el inventario de plantas reseñado prueba, a través de la diversidad de su contenido, la formación botánica del monje responsable de su botica; a la par que nos informa de la trama de relaciones personales e institucionales de la Botánica española de finales de la Ilustración.

\section{Notas}

1. Archivo del Palacio Real de Madrid, signatura, Archivo General, caja 22284, expediente 8.

2. Sólo una Datura y una Primula son nombradas con nomenclatura polinominal.

3. Cf. F. Muñoz Garmendia. Diarios y trabajos botánicos de Luis Neé. Barcelona: Ministerio de Defensa / Museo Naval / Lunwerg editores, 1992.

4. Cf. M.E. Alegre Pérez. Bol. Soc. Esp. Hist. Farmacia, 30(118): 161-168.

5. Copia del informe realizado por Casimiro Gómez Ortega, en Madrid a 13-III-1784 (Archivo del Real Jardín Botánico de Madrid [Arch. RJB], leg. VI, 2,2, [fol. 8]).

6. Copia del certificado extendido por Luis Blet a favor de Luis Neé, 24-VIII-1783 (Arch. RJB, leg. 6,2,2 [fol. 3]).

7. Arch. RJB, leg. 1,3,2, 1 [22 folios]

Dirección de los autores. Departamento de Farmacia y Tecnología Farmacéutica. Facultad de Farmacia. Universidad Complutense de Madrid. * Autor para correspondencia: rbasante@farm.ucm.es

\title{
38. SOBRE LOS ÚLTIMOS AÑOS DEL BOTÁNICO MANUEL GONZÁLEZ DE JONTE (1827-1867)
}

Alberto GOMIS

Recibido el 3 de septiembre de 2008, aceptado para su publicación el 15 de septiembre de 2008 Publicado "on line" en septiembre de 2008

Manuel González de Jonte y Villamil (1827-1867) autor, en 1849, del primer Manual de Botánica ${ }^{1}$ en el que se expusieron en nuestro país la ideas de Schleiden sobre la división celular ${ }^{2}$, mereció nuestro atención en un trabajo amplio que se presentó en el marco del III Congreso de la Sociedad Española de Historia de las Ciencias ${ }^{3}$. Allí 
señalábamos su marcha a Cuba a finales de los cincuenta, sus trabajos -en la Isla- como naturalista, médico y publicista (fue director del semanario Eco de la literatura cubana y de La Prensa); su matrimonio con Elvira Buigas y Ferrán (natural de Matanzas); el nacimiento de su hijo, Manuel González de Jonte y Buigas, que sería médico; así como su fallecimiento en la isla en 1867.

Nueva documentación, encontrada entre los fondos de Hacienda (Sección $3^{\text {a }}$ Montepío de Ultramar) que se custodian en el Archivo General de la Administración, nos ha permitido precisar algunos aspectos de los últimos años de vida de González de Jonte. Dicha documentación se genera a partir de la instancia que, el 3 de marzo de 1868 , presenta Ángela Sauca y Rada, como viuda de Manuel González de Jonte, en solicitud de pensión y a la que acompaña partidas de casamiento y de defunción ${ }^{4}$.

A la vista de la documentación apuntada, se constata que Manuel González de Jonte y Ángela Sauca contrajeron matrimonio el 30 de noviembre de 1864 en la Iglesia parroquial mayor o Sagrario de la Catedral de La Habana. Ambos eran, en esos momentos, viudos. El primero de, la ya mencionada, Elvira Buigas; la segunda, que era natural de Tarazona (Zaragoza), de José Alvert.
Durante sus últimos años, Manuel González de Jonte fue catedrático de Zoología, Mineralogía y Botánica de las Ciencias Profesionales Superiores de la Ciudad de La Habana. Su fallecimiento tuvo lugar, en dicha ciudad, el 27 de agosto de 1867 , a la edad de treinta y nueve años. Al día siguiente su cuerpo fue sepultado en un nicho del cementerio general.

\section{Notas.}

1. M. González de Jonte. Manual de Botánica para uso de las personas que se dedican a la botánica de ampliación, y de la organografía y fisiología vegetal. Madrid: Imprenta y Librería de Román Matute, 1849.

2. A. Gomis. Actas II Congreso de la Sociedad Española de Historia de las Ciencias, 2: 133149. 1984.

3. A. Gomis Blanco; F. Pelayo López y J. Fernández Pérez. Actas del III Congreso de la Sociedad Española de Historia de las Ciencias, 3: 291-310. 1986.

4. "Sanca [sic] Rada, Ángela. Viuda de Manuel González de Jonte". Archivo General de la Administración, Hacienda. Caja 21.453.

Dirección del autor. Departamento de Ciencias Sanitarias y Médico-Sociales. Edificio de Medicina. Campus Universitario. Ctra. MadridBarcelona, Km 33,600. Universidad de Alcalá. *Autor para correspondencia: alberto.gomis@uah.es 